\title{
The Protective Effect of Field Mint Leaves in Reducing Stomach Ulcer in Rats Induced by Aspirin
}

\author{
Vanitha Ratha Krishnan, ${ }^{1}$ Januarsih A. Rachman, ${ }^{2}$ Abdul Hadi Hassan ${ }^{3}$ \\ ${ }^{1}$ Faculty of Medicine Universitas Padjadjaran, ${ }^{2}$ Department of Anatomy and Cell Biology Faculty \\ of Medicine Universitas Padjadjaran, ${ }^{3}$ Department of Pathology Anatomy Faculty of Medicine \\ Universitas Padjadjaran/Dr. Hasan Sadikin General Hospital Bandung
}

\begin{abstract}
Background: Stomach mucosal wall erosion is caused by the imbalance of the aggressive factors and mucosal defensive factors due to the common causes such as the side effect of consuming non-steroidal antiinflammatory drugs. Field mint (Menthaarvensis) leaves have been used as an alternative option to cure and prevent the gastric problems. The aim of this study was to analyze the protective effect of Field mint leaves infusion in reducing stomach ulcer in rats induced by Aspirin.

Methods: The experimental study was conducted at Histology Laboratory of Faculty of Medicine, Universitas Padjadjaran, Bandung. Sixteen rats were divided into 4 groups randomly: group I (control negative group), group II (control positive group, given 90mg/day Aspirin, group III (the treatment group, given 5cc of Field mint leaves infusion and $90 \mathrm{mg}$ Aspirin) and group IV (the treatment group, given 5.6 $\mathrm{ug}$ of Misoprostol and $90 \mathrm{mg}$ Aspirin). Mucosal wall erosions were determined by using microscope. Data were analyzed using non-parametric Kruskal-Wallis test and Mann-Whitney U-test (CI 95\% and p-value<0.05)

Results: Group II had high score of mucosal wall erosions after given only aspirin. In group III and IV, the score of mucosal wall erosions were low. However there was no difference in score of mucosal wall erosions between group III-IV $(\mathrm{p}<0.05)$

Conclusions: Field mint (Menthaarvensis) leaves infusion is able to prevent stomach mucosal wall erosions induced by Aspirin as misoprostol does. [AMJ.2015;2(3):363-68]
\end{abstract}

Keywords: Aspirin, field mint (Menthaarvensis), stomach mucosal wall erosions

\section{Introduction}

Stomach ulcer is resulted from disparity of antagonistic gastric luminal factors such as acid and pepsin and defensive mucosal barrier function. Many environmental and host factors can lead to an ulcer formation. This is caused by increasing the gastric acid secretion or weakening the mucosal barrier. One of the most significant causes of the ulcer is the use of Non-Steroidal Anti-Inflammatory Drugs such as Aspirin. Aspirin causes an inhibition of cyclooxygenase enzyme (COX) which inhibits endogenous prostaglandin especially Prostaglandin E1 (PGE1), Prostaglandin E2 (PGE2) and Prostaglandin analogue (PGI2). Thus, mucosal defense is in breached. Prostaglandin is accountable in regulating mucous cell secretion and since COX inhibits prostaglandin causing the barrier function is disrupted. The decreased Prostaglandin inhibits basal bicarbonate secretion from mucosa and augmentation of acid production..$^{1-4}$

Traditional medicine remains widespread in many countries due to its affordability and availability. For example is the use of Field mint plant which is a constant plant belonging to the Mentha genus. This mint plant is found worldwide such as in Europe, Asia and North America. Its mutual names include Field mint, Wild mint or Corn mint. Field mint is well-known by its scientific name Mentha arvensis. The leaves of this herbal plant have a fresh mint aroma and used for cooking and medicinal purposes. Furthermore, the essential oil extracted from the leaves also has

Correspondence: Vanitha Ratha Krishnan, Faculty of Medicine, Universitas Padjadjaran, Jalan Raya Bandung-Sumedang Km.21, Jatinangor, Sumedang, Indonesia, Phone: +628170204955 Email: vanitha102@hotmail.com 
Table 1 Scoring of the Extend of Mucosal Wall Erosion

\begin{tabular}{lc}
\hline & Score \\
\hline No erosion & 1 \\
Erosion only at the surface of mucosal layer & 2 \\
Erosion at $1 / 3$ upper region of gastric gland & 3 \\
Erosion at $1 / 3$ middle region of gastric gland & 4 \\
Erosion at $1 / 3$ lower region of gastric gland & 5 \\
Erosion at muscularis mucosa & 6 \\
\hline
\end{tabular}

many advantages. Field mint tea is mainly used as an invigorating drink and condiment. ${ }^{5-9}$

Moreover, Field mint leaves have various medicinal properties in preventing gastrointestinal disorders. Field mint oil can be used for both intrinsic and extrinsicindications. The food and drug administration (FDA) approved the oil of mint a "Generally Regarded as Safe" (GRAS) status. Mint leaves have many benefits such as rich of antioxidants, for example phenols, vitamins including vitamin A, beta carotene and vitamin-C. ${ }^{6}$ Thus, the present study was undertaken to determine the protective effects of $5 \mathrm{cc} /$ day Field Mint leaves infusion in the experimental erosion of stomach mucosal layer in rats induced by Aspirin. ${ }^{5-9}$

\section{Methods}

In this study, the subjects used were 16 of 12 weeks white male Wistar rats with 200 grams each adapted for one week. The rats were obtained from the Pharmacological Laboratory, Faculty of Medicine, Universitas Padjadjaran. The materials used in this study were fresh Field mint (Mentha arvensis) leaves. The leaves were purchased from the local vegetable supermarket (Jatos) in Jatinangor and were identified. The leaves were shade dried, finely powdered and made into an infusion. A total of 30 grams Field mint (Mentha arvensis) leaves powder was added with $500 \mathrm{ml}$ of water and an additional of extra water 2 times of the material weight $(8 \mathrm{ml})$ in a special pan to make the infusion. Then, heated over a water bath for 15 minutes, calculated from the temperature in the pot at $900 \mathrm{C}$, and stirring was done occasionally. The infusion was filtered while still hot.39 The leaves were given in the form of $5 \mathrm{cc} /$ rat infusion per oral. This particular dosage was given to attain an optimum effect of the study.

Drugs used in this study were Aspirin and Misoprostol. This study was an experimental laboratory study using a simple randomization design plan. A total of 16 rats were used as experimental animals and grouped randomly into 4 groups using random allocation method as follows: Group I which was the negative control group was given aqueous solution. Group II which was the positive control group was given aspirin solution (90mg). Group III, the treatment group was given aspirin solution (90mg) and field mint (Mentha arvensis) leaves infusion (5cc/rat) and Group IV, also a treatment group was given Aspirin solution (90mg) and Misoprostol (3.6 $\mu \mathrm{g})$.

Before the study, the rats were adapted to the laboratory environment for one week. The rats were given food in the form of pellets and also water as needed. The rats were weighed every day and at the end of adaptation period and were observed closely to make sure they are healthy. Next, all rats went on a fast. Over the next five days, every morning each treatment group was given a respective drug: Treatment group III was given $5 \mathrm{cc} / \mathrm{rat}$ field mint (Mentha arvensis) leaves infusion and treatment group IV was given $3.6 \mu \mathrm{g}$ of Misoprostol. One hour later, group III and IV were given $90 \mathrm{mg}$ Aspirin. At the end, the rats went on a fast for 24 hours. Finally, all rats were sacrificed with anesthesia using diethyl ether. The rats were dissected by laparotomy to obtain the gaster.

The gastric mucosal layer (pyloric part) was then observed microscopically using the $100 \mathrm{x}$ and 400x magnifications after a fixation and staining. The depth of the mucosal wall erosion were observed and noted in each group. The extend of mucosal wall erosion were classified according to Wattimena (1982) (Table 1). ${ }^{10}$

The statistical analysis was conducted by using a computer. The statistical test showed CI $95 \%$ and $p$-value $<0.05$ (significant) and $p$-value $<0.01$ (highly significant). The microscopic data were analyzed by KruskalWallis test, to assess the median difference among those various groups. If the Kruskal- 


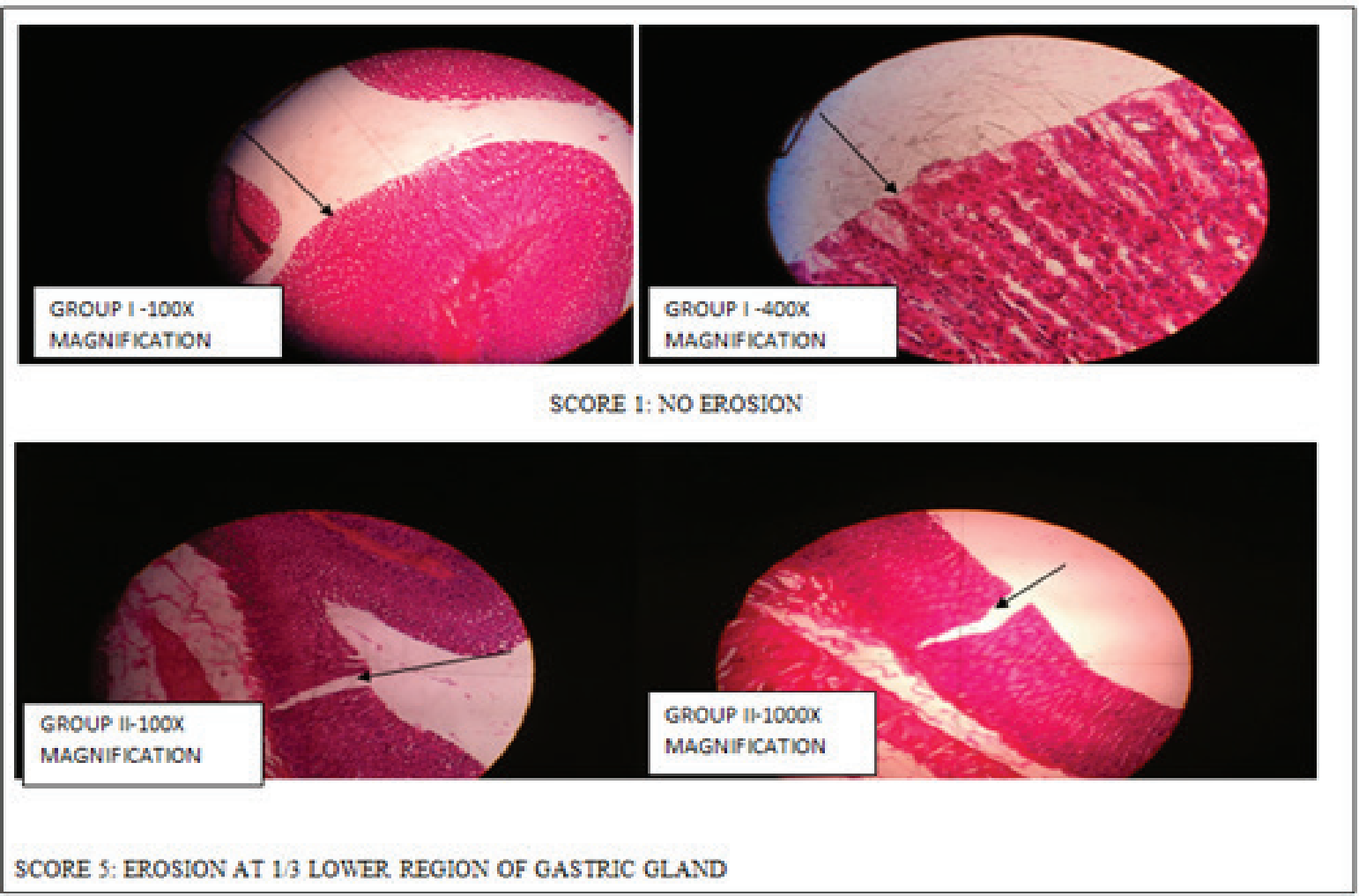

Figure 1 Microscopic Observation of Stomach Mucosal Erosion in Group I (Control Group) and Group II (Aspirin Group)

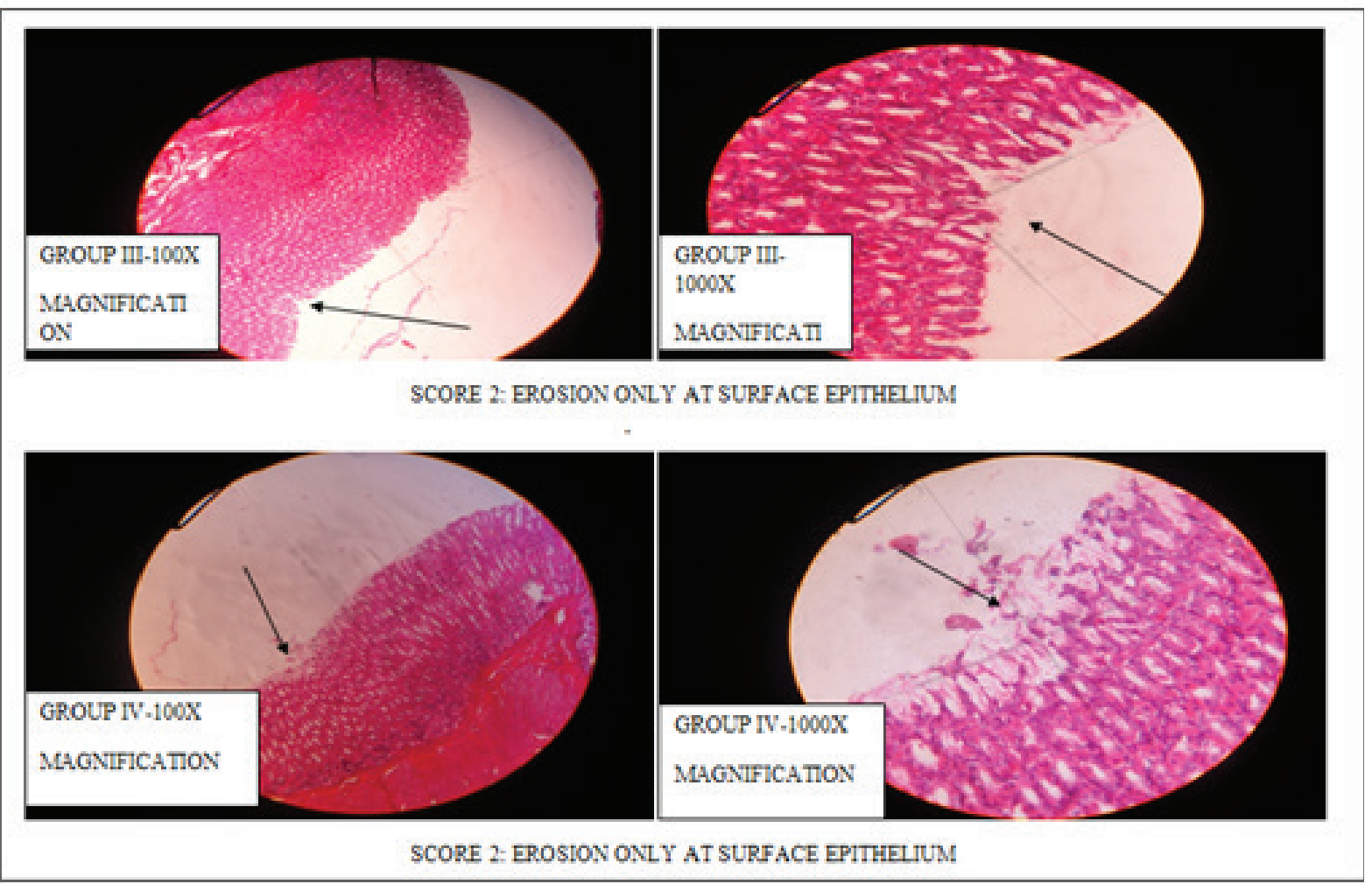

Figure 2 Microscopic Observation of Stomach Mucosal Erosion in Group III (Field mint leaves Infusion) and Group IV (Misoprostol) 
Table 2 Effects of Field mint Leaves Infusion on Aspirin Induced in Gastric Mucosal Erosions Wattimena Score)

\begin{tabular}{cccccccccc}
\hline Group & \multicolumn{7}{c}{ Wattimena Score } & \multicolumn{2}{c}{ p } \\
\hline & 1 & 2 & 3 & 4 & 5 & 6 & Median & Range & 0.000 \\
Group I & $89 \%$ & $10 \%$ & $1 \%$ & $0 \%$ & $0 \%$ & $0 \%$ & 1 & 2 & \\
Group II & $12 \%$ & $21 \%$ & $20 \%$ & $16 \%$ & $24 \%$ & $7 \%$ & 3 & 5 & \\
Group III & $71 \%$ & $18 \%$ & $10 \%$ & $1 \%$ & $0 \%$ & $0 \%$ & 1 & 3 & 3 \\
Group IV & $61 \%$ & $28 \%$ & $9 \%$ & $2 \%$ & $0 \%$ & $0 \%$ & 1 & 3 \\
\hline
\end{tabular}

Note $: \mathrm{n}=100$ areas of observation in each group; group I (control); group II (Aspirin); group III (FLI); group IV (Misoprostol); $\mathrm{p}<0,05$ (significant); $\mathrm{p}<0.01$ (highly significant)

Wallis test is significant, the Mann-Whitney test was used to assess the median differences between two groups: Group I-II; Group I-III; Group I-IV; Group II-IV; Group III-IV.

\section{Results}

The microscopic results were obtained by microscopic evaluation to the stomach mucosal layer on the histological slide using the 100X and 400X light microscope. Data were collected during the evaluation by observing the erosions of the mucosal layer of the rat's stomach. The severity of gastric mucosal erosions was as illustrated below (Figure 1 and Figure 2).

The microscopic Wattimena score data collected from all four groups were analyzed by using non parametric Kruskal-Wallis test to asses statistical differences between various groups of animals with CI $95 \%$ and $\alpha=5 \%$. Ho rejected when p-value $<0.05$ and accepted when p-values $>0.05$. From the statistical test, it is shown that there was a difference between those groups (Table 2).

The microscopic data collected were then analyzed by using Mann-Whitney $U$ test to asses statistical difference between two groups of animals with CI $95 \%$ and $\alpha=5 \%$. Ho rejected when $p$ value $<0.05$ and accepted when $p$ value $>0.05$. From the statistical test, there were differences between group I-II, group I-III, group I-IV, group II-III, group IIIV. However, there was no difference between group III-IV (Table 3).

\section{Discussion}

It was proven from the results of the present investigation that the leaves infusion of field mint (Mentha arvensis) possesses a protective effect in aspirin- induced acute ulcer. It has shown a significant reduction in the gastric lesions of the aspirin treated groups of animals. Although the etiology of the gastric ulcer is unknown in most of the cases, it is generally accepted that they are resulted from an imbalance between aggressive factors and the maintenance of mucosal wall integrity through the endogenous defense.

From the microscopic results as stated above, it seems that aspirin can cause the erosions of the stomach mucosal layer. Various factors are identified to be the risk factors and predisposing factors for the stomach mucosal wall erosion due to aspirin consumption. These factors have a close relation with the pathogenesis of Aspirin-induced gastric ulcer. The disturbance in mucosal resistance allows the injury by endogenous factors such

Table 3 Statistical Comparison among Groups

\begin{tabular}{ccc}
\hline Comparison Between Groups & Mann-Whitney U & p-value \\
\hline I vs II & 802.000 & 0.000 \\
I vs III & 4053.500 & 0.001 \\
I vs IV & 3558.000 & 0.000 \\
II vs III & 1322.000 & 0.000 \\
II vs IV & 1505.000 & 0.000 \\
III vs IV & 4549.500 & 0.188 \\
\hline
\end{tabular}

Note $: \mathrm{n}=100$ areas of observation in each group; p-value was calculated using Mann Whithney U test; group I (control); group II (aspirin); group III (FLI); group IV (misoprostol); $\mathrm{p}<0,05$ (significant); $\mathrm{p}<0.01$ (highy significant) 
as acid, pepsin, and bile salts. Furthermore, aspirin administration for acute ulcer model of animals in this study was sufficiently induced mucosal erosions of the stomach even if it took four hours for ulcer induction before sacrificing. This was proven by the significant results of theAspirin group (Group II) mucosal wall erosions compared to the control group (Group I) which only received aqueous solution and daily normal diet pellet.

After ingestion of NSAIDs, the structural damage to the stomach surface epithelium occurs. The oxygen derived free radicals plays a big impact in the mechanism of aspirin induced gastric ulcers. Aspirin induces the reactive oxygen metabolites in rats, which contributes to mucosal injury. The potential antioxidant protective effect of Field mint leaves on gastric mucosal tissue is a topic of high current interest. ${ }^{11-13}$

The Aspirin group (Group II) showed a significant increase in ulceration whereas in the Field mint leaves infusion group (Group III), there was a significant reduction of the aspirin effect. Field mint leaves are used as herbal remedies in folk medicine. Menthol, caryophyllene and flavonoids which are the active agents in Field mint leaves are known to possess a potent antiulcer activity. It also reduces gastric acid secretion induced by histamine in rats. Field mint oil comprises vitamins $\mathrm{A}$ and $\mathrm{C}$, omega- 3 fatty acids, and minerals including potassium, manganese, iron, magnesium, calcium, and copper which increase the production of mucosal barrier in stomach mucosal wall.

Field mint leaves infusion inhibited the increase of the stomach mucosal wall lesions in Aspirin induced lesions in rats. Field mint leaves infusion pretreatment offered a protection against the action of aspirin showed that the presence of some antioxidant phytoconstituents might have the gastric mucosa from free radical-induced damage. The effective scavenging of free radicals by Vitamin C and Carotene may have reduced the progressive ulceration. Field mint leaves contain flavonoids which can reduce gastric tissue histamine content. This fact in turn may have inhibited gastric secretions. Carotene is a natural fat-soluble pigment which has antioxidant activity in vitro demonstrated that can take up singlet oxygen scavenge peroxyl radicals and inhibit lipid peroxidation..$^{11-13}$

In the present study, it was found that animals in the Control group (Group I) also developed some erosions through microscopic observation. This could be due to the normal physiological changes in the gastric mucosal cells regulation as a response to the environmental factors in the laboratory such as temperature. The cells of the gastrointestinal tract have a rapid turnover rate, which makes its mucosa become one of the most rapidly proliferating tissues in the human body. Under normal circumstances, cell populations within the gastrointestinal tract are maintained at a dynamic state because the cell loss due to the exposure of the gastric mucosa to $\mathrm{pH}$, osmolarity and temperature is balanced by a continuous cell renewal.

The other possible reason of the control group (Group I) having mucosal wall erosions was due to its non-inflamed prior mucosal condition. Inflamed gastric tissue is more resistant to aspirin-induced damage than noninflamed gastric tissue. Physiologically, acid secretions in the stomach are under control of nervous and endocrine systems. The $\mathrm{pH}$ can reach a minimum level of 0.8 . Fasting for long periods of time can cause acidic conditions which leads to mucosal wall erosions. During the study, the rats went on a fast for 24 hours prior to sacrifice.

Furthermore, the gastric mucosal erosions of rats belonged to the Field mint leaves Infusion Group (Group III) did not show a significant result when it was compared to the Misoprostol group (Group IV).The reason for this condition was due to the very similar mechanism of action of both Field mint leaves and Misoprostol which has an antioxidant effect to free radicals. For these results, it can be concluded that the $5 \mathrm{cc} /$ day of Field mint leaves infusion had an adverse protective effect toward aspirin-induced gastric erosions in rats. The study limitation was that the concentration of mint leaves infusion used was only one so the different effect from different concentration cannot be found. Further study should be conducted using several concentration with larger sample size.

\section{References}

1. Katzung BG, Masters SB, Trevor AJ. Basic and clinical pharmacology. $11^{\text {th }}$ ed. New York: McGraw-Hill Companies Inc; 2009. p. 584.

2. Mitchell J.Non-steroidal anti-inflammatory analgesic drugs. AnaesthesiaUK. 2006 [Cited 2012 April 21]. Available from: http://www.frca.co.uk/article. aspx?articleid=100633.

3. Sinatra RS, Jahr JS, Watkins-Pitchford JM. The essence of analgesia and analgesics. 
Cambridge: Cambridge University Press; 2011.

4. Gabriel SE, Jaakkimainen L, Bombardier C. Risk for serious gastrointestinal complications related to use of nonsteroidal anti-inflammatory drugs: a meta-analysis. Ann Intern Med. 1991; 115(10):787-96.

5. Pandey AK, Rai MK, Acharya D. Chemical composition and antimycotic activity of the essential oils of corn mint (Mentha arvensis) and lemon grass (Cymbopogon flexuosus) against human pathogenic fungi. Pharmaceutical Biology. 2003; 41(6):421-5.

6. Moerman D. Native American ethnobotany: a database of Native American foods, drugs, dyes, and fibers of Native American peoples derived from plants. Dearborn Michigan: University of Michigan Dearborn; 2003.

7. Dwivedi D, Khandelwal G, Patidar RK, Singh V. Antimicrobial activity of mentha arvensis against clinical isolates of human cariogenic pathogens- an in-vitro study. IJPSR. 2012;3(5):1355-60.

8. Dorman HJ, Koșar M, Kahlos K, Holm
Y, Hiltunen R. Antioxidant properties and composition of aqueous extracts from Mentha species, hybrids, varieties, and cultivars. J Agric Food Chem. 2003; 51(16):4563-9.

9. Akram M, Uzair M, Malik NS, Mahmood A, Sarwer N, Madni A, et al. Mentha arvensis Linn.: a review article. J Med Plants Res. 2011; 5(18):4499-503.

10. Wattimena JR. L'hypoproteinemiae experimentale chez le rat, exploritation pharmacocinetique et pharmacologie du modele. These doctor d'etat es screces pharmaceutique. Montpellier: Universite De Mountepellier; 1982.

11. McCord JM. The evolution of free radicals and oxidative stress. Am J Med. 2000;108(8):652-9.

12. Becker JC, Domschke C, Pohle T. Current approaches to prevent NSAID-induced gastropathy - COX selectivity and beyond. Br J Clin Pharmacol. 2004; 58(6):587-600.

13. Rahman K. Studies on free radicals, antioxidants, and co-factors. Clin Interv Aging. 2007; 2(2):219-36. 